\title{
Effects of Ambient Temperature and Wind Speed on Performance of Monocrystalline Solar Photovoltaic Module in Tripura, India
}

\author{
Tanima Bhattacharya, ${ }^{1}$ Ajoy K. Chakraborty, ${ }^{1}$ and Kaushik Pal ${ }^{2}$ \\ ${ }^{1}$ Department of Electrical Engineering, National Institute of Technology, Agartala 799055, India \\ ${ }^{2}$ Department of Mechanical and Industrial Engineering, Indian Institute of Technology, Roorkee, Uttarakhand 247667, India \\ Correspondence should be addressed to Kaushik Pal; pl_kshk@yahoo.co.in
}

Received 9 July 2014; Revised 12 September 2014; Accepted 15 September 2014; Published 25 September 2014

Academic Editor: Charles Michael Drain

Copyright ( $) 2014$ Tanima Bhattacharya et al. This is an open access article distributed under the Creative Commons Attribution License, which permits unrestricted use, distribution, and reproduction in any medium, provided the original work is properly cited.

The effects of ambient temperature and wind speed on the performance analysis of a monocrystalline silicon solar photovoltaic module have been analyzed in a particular location called Tripura, India, for the period of 2012-2013. The research work has been carried out by monitoring the variation of module efficiency with ambient temperature and wind speed. A statistical analysis has also been done and the result indicates that the values of correlation coefficient are $96 \%$ and $68 \%$ for ambient temperature and wind speed, respectively, considering confidence level of $95 \%$.The result shows that there is a strong positive linear relationship between module efficiency and ambient temperature and a moderate positive linear relationship between module efficiency and wind speed. The deviation from the standard test condition (STC) affects the generation of output power while designing green buildings in Tripura.

\section{Introduction}

Since the use of energy has become an integral part of our life, its supply should be secure and sustainable. The energy requirement of the world is ever increasing. The increasing energy demands put a lot of pressure on the conventional energy sources. Therefore, there is a need for alternative energy sources which can provide us energy in a sustainable manner

The obvious choice of a clean energy source, which is abundant and could provide security for the future development and growth, is the sun's energy. Apart from this, sun is also available to us indirectly in the form of wind energy. Wind energy globally has a successful alternative technology for electrical energy generation. Recently, there has been an enormous increase in the understanding of the operational principle of photovoltaic devices, which led to a rapid increase in the power conversion efficiencies of such devices. Solar cells vary under temperature changes which will affect the power output of the cell. The researchers also indicated that the desired efficiency of PV module can be achieved by changing the ambient temperature around the PV module [1].

Solar modules work best in certain weather conditions, but, since the weather is always changing, most solar photovoltaic modules do not operate under normal operating conditions. The performance of a PV system depends not only on its basic characteristics but also on the environmental issues. One such environmental issue like the ambient temperature plays an important role in the photovoltaic conversion process [2].

The solar modules are manufactured at STC, but when they are used for domestic purposes in a particular area, the environmental issues like ambient temperature as well as wind speed also affect the performance of the module for that particular locality. The solar module's performance varies with actual location and prevailing environmental conditions to which they are subjected [3]. The photovoltaic output performance varies with atmospheric factors. Since the intensity of radiation is changing at every instant, it is obvious that energy production by the solar cells will also 
be changing. It has been observed that the power delivered by the PV systems at a certain instant is still very much a function of weather factors [4].

The efficiency of the module has dependency on the environmental parameters [5]. Meteorological data such as solar radiation, ambient temperature, relative humidity, and wind speed are accepted as dependable and widely variable renewable energy sources [6]. Different types of modules and arrays studied with different climates of different regions have been taken into account by researchers [7]. Among all major meteorological parameters, only ambient temperature and wind speed have been considered for the present study.

The specification given by the manufacturer does not actually give the accurate result while analyzing the performance of the photovoltaic (PV) system; thus the local environmental parameters must be taken into account [8]. In the north eastern region of India no such study has been done before to check whether the specification given by the manufacturer met the actual environmental conditions. In our recent study we have considered the module of the solar home lighting systems which are actually installed in the premises of individual beneficiaries of rural and urban areas of Tripura by the government authority. Now, in actual case once the systems are installed, it is quite impossible to monitor the performance of the systems. Photovoltaic installations majorly get affected by cell temperature, soiling, and so forth. But the functioning of solar devices at any time depends on the ambient variables also. Here for this reason an attempt has been taken to investigate how the performance of the photovoltaic module affected by the environmental parameters like ambient temperature and wind speed. In the recent study, a statistical analysis has been done with the Portable Statistica 8 software to show how the ambient temperature and wind speed of the solar module are correlated with efficiency. It is seen from the analysis that there is a direct proportionality between ambient temperature and solar photovoltaic module efficiency.

\section{Materials and Methods}

The experiment has been done with solar photovoltaic module no. 03018119, manufactured by M/S Tata BP Solar India Ltd., India, as shown in Figure 1. A digital multimeter (M3900) is used to measure the short circuit current and open circuit voltage. One digital thermometer (MS2101) has been used to check the ambient temperature, anemometer to measure wind speed, and TENMARS TM -207 solar power meter to measure the intensity of the solar radiation as follows:

solar type: monocrystalline,

maximum power: $37 \mathrm{~W}$,

cell area: 0.3239 sq.meters,

open circuit voltage: $21 \mathrm{~V}$,

short circuit current: $2.50 \mathrm{Amp}$,

voltage at maximum power: $16.4 \mathrm{~V}$,

current at maximum power: $2.26 \mathrm{Amp}$.

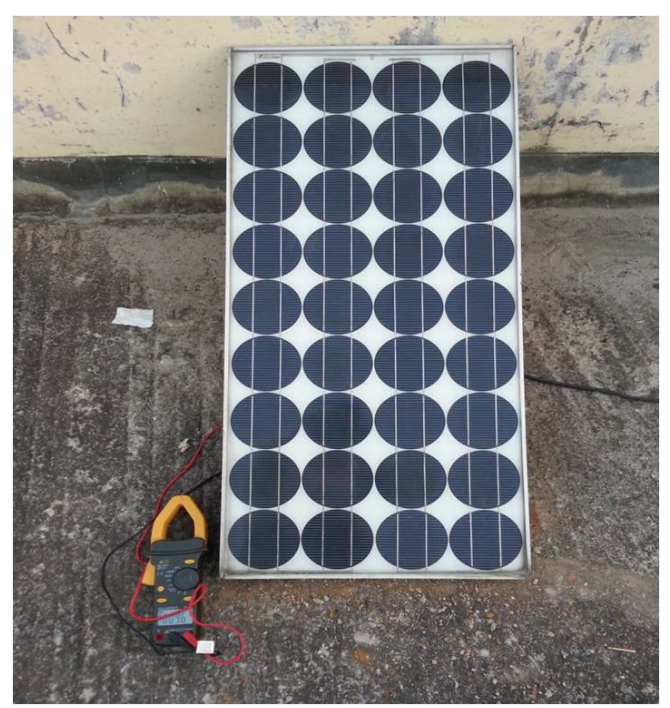

FIGURE 1: Solar photovoltaic module.

The daily efficiency $(\eta)$ of the PV module can be determined from the following relationship:

$$
\eta=\frac{\sum_{i=1}^{i=n} P i}{A \sum_{i=1}^{i=n} E i},
$$

where $P=\mathrm{PV}$ module power in watt and $A=\mathrm{PV}$ module area in square meter.

The values of efficiency were calculated for each day for one hour interval and from that the daily monthly average values were calculated. The daily monthly average values of ambient temperature were calculated by the digital thermometer.

For the present study the solar photovoltaic module was placed on the roof top of Vigyan Bhawan, Agartala, Tripura, India. General variation in efficiency with respect to ambient temperature and wind speed has been evaluated from (1) with the required data. The values of ambient temperature and wind speed at an interval of 1 hour were recorded for each day and from that daily average and monthly average values of ambient temperature and wind speed have been measured. Table 1 shows the variation of monthly average values of ambient temperature and wind speed from May 2012 to April 2013. Also monthly average values of efficiency of the photovoltaic module for the same period have been calculated as shown in Table 1. The aim of the present study is to find out the variation of efficiency of solar photovoltaic module with ambient temperature and wind speed. Dependency of efficiency of solar photovoltaic module on different factors except ambient temperature and wind speed are neglected for the analysis. The simple correlation coefficient $R$ has been determined considering efficiency as dependent variable and ambient temperature and wind speed as independent variable separately.

Figure 2 shows the variation of monthly average values of ambient temperature for the period of May 2012 to April 2013. The ambient temperature varies with different months of the year throughout the period of the study for a particular area. 
TABLE 1: Variation of efficiency with ambient temperature and wind speed for the period from May 2012 to April 2013.

\begin{tabular}{lccc}
\hline Month & $\begin{array}{c}\text { Ambient } \\
\text { temperature }(\%)\end{array}$ & $\begin{array}{c}\text { Wind speed } \\
(\mathrm{m} / \mathrm{s})\end{array}$ & Efficiency (\%) \\
\hline May 2012 & 33.9 & 2.6 & 13.32 \\
June 2012 & 32.5 & 3.2 & 13.01 \\
July 2012 & 32.4 & 3.8 & 12.98 \\
August 2012 & 32.4 & 1.7 & 12.98 \\
September 2012 & 32.4 & 1.3 & 12.98 \\
October 2012 & 31.2 & 1 & 12.72 \\
November 2012 & 28.6 & 1.1 & 12.14 \\
December 2012 & 24.1 & 1.7 & 12.23 \\
January 2013 & 21.2 & 1.2 & 11.50 \\
February 2013 & 22.4 & 1.6 & 11.77 \\
March 2013 & 35 & 4.3 & 13.56 \\
April 2013 & 35.8 & 3.2 & 13.74 \\
\hline
\end{tabular}

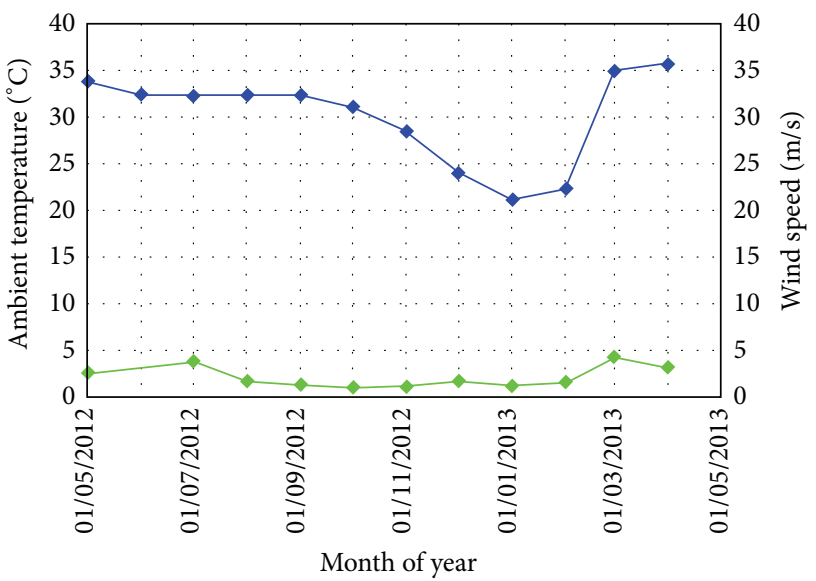

FIGURE 2: Variation of monthly average values of ambient temperature and wind speed for the period from May 2012 to April 2013.

\section{Results and Discussions}

Figure 2 indicates the monthly average variation of ambient temperature and wind speed for the period of May 2012 to April 2013. From the figure it is seen that the ambient temperature got a peak value for the month of March, April, and May. The minimum values of ambient temperature found in the month of December, January and February. The maximum values of ambient temperature are due to high solar radiation. The temperature remains almost the same for the rest of the months from July to September. Accordingly, two distinct maximum values are observed in the month of July and March for wind speed. For April and May there is slight reduction in wind speed. For the period of August to February the values of wind speed remain almost the same.

In Figure 3, the three-dimensional surface plot reveals that the estimating ambient temperature, wind speed, and output efficiency are closely related. It can be seen from this figure that the correlation between the module efficiency and ambient temperature/wind speed is nonlinear.

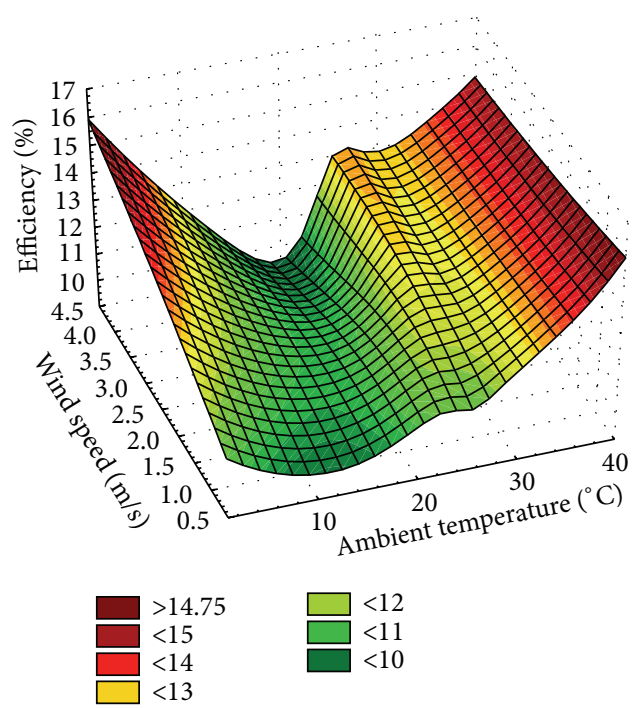

FIGURE 3: Monthly average values of solar module efficiency for the year 2012-2013.

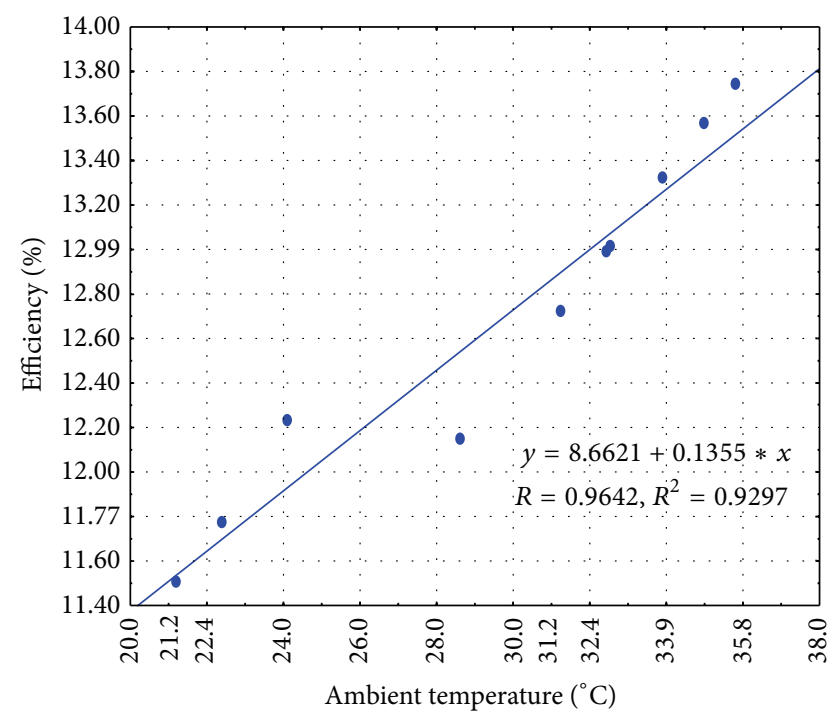

Figure 4: Monthly average values of solar module efficiency and ambient temperature for the year 2012-2013.

Figure 4 shows the variation of monthly average values of efficiency of the PV module against the ambient temperature for the period of study. It is seen from the pattern of the graph that the ambient temperature and efficiency are correlated with each other. The statistical analysis shows that the value of correlation coefficient $(R)$ is 0.9642 , which confirms that a strong positive correlation exists between ambient temperature and efficiency. The regression equation obtained from the analysis is

$$
Y=8.6621+0.1355 * X
$$

where $X$ denotes independent variable ambient temperature and $Y$ denotes the dependent variable solar photovoltaic 


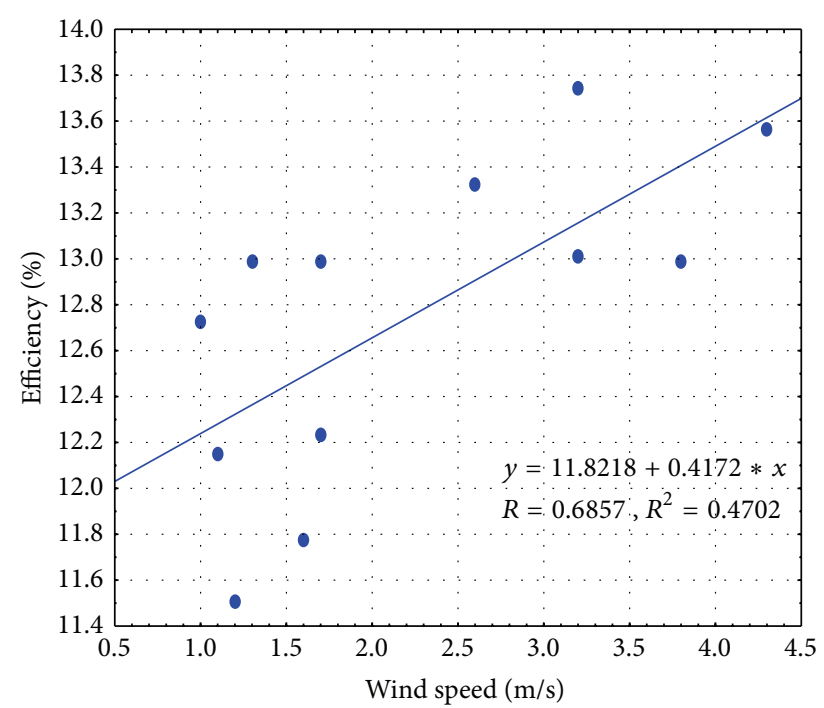

FIGURE 5: Monthly average values of solar module efficiency and wind speed for the year 2012-2013.

module efficiency. Again the value of coefficient of determination $\left(R^{2}\right)$ becomes 0.9297 , which indicates that $92.97 \%$ of the total variation in $Y$ can be explained by the linear relationship between $X$ and $Y$ (as described by the regression equation). In other words, the regression line passes through almost all the points which mean that there is a direct proportionality between the two variables.

Figure 5 shows the variation of monthly average efficiency of the PV module against the wind speed for the period of study. Here, the value of correlation coefficient $(R)$ is 0.9642 , which means that there is a moderate positive correlation between wind speed and efficiency. The regression equation obtained from the analysis is

$$
Y=8.6621+0.1355 * X
$$

where $X$ denotes independent variable wind speed and $Y$ denotes the dependent variable solar photovoltaic module efficiency. In this case coefficient of determination $\left(R^{2}\right)$ becomes $47.02 \%$ which explains a moderate positive linear relationship between the module efficiency and wind speed as $52.98 \%$ of the total variation in $Y$ remains unexplained.

Different linear and nonlinear equations have been developed to correlate the PV module performance in terms of electrical power output with the operating temperature. Sansui et al. carried out statistical analysis where the favorable conditions of conversion of solar energy to electricity have been shown [9]. But in the recent study, the statistical analysis has been done on correlation concept considering confidence limit of $95 \%$ for the two different ambient parameters, namely, ambient temperature and wind speed. Also as Tripura is a hilly area, the ambient temperature differs from the plane area on different seasons. The analysis has been done for twelve months period to cover seasonal effects.

\section{Conclusion}

In this paper, the effects of temperature on photovoltaic module output performance were investigated. It is seen from the result that the correlation between the efficiency and ambient temperature is very good as compared to the correlation between efficiency and wind speed. The ambient temperature has a positive correlation with the efficiency of the PV system which indicates that ambient temperature plays an important role in performance analysis. Also, there is a direct proportionality between the efficiency of the PV system and the ambient temperature of the locality. It can be concluded that the ambient temperature can be preferred for predicting the performance of photovoltaic module compared to wind speed for the present area of study. Actually when the power plants are installed at different rural areas of the state, it is seen that though the modules are placed at due south, the output power generated does not meet the desired level. This may be due to the modules manufactured at STC. Therefore, the deviation from the standard test condition affects the generation of output power. So, while designing green buildings, these ambient parameters should also be taken into consideration instead of considering only the orientation of the solar PV modules.

\section{Nomenclature}

PV: Photovoltaic

STC: Standard test condition

W: Watt

V: $\quad$ Volt

Amp: Ampere

$\eta$ : $\quad$ Efficiency of solar module (\%)

T: $\quad$ Ambient temperature $\left({ }^{\circ} \mathrm{C}\right)$

$r$ : Multiple correlation coefficient

A: $\quad$ Area of module

$R: \quad$ Correlation coefficient

$R^{2}$ : Coefficient of determination

$X: \quad$ Independent variable

$Y$ : Dependent variable.

\section{Conflict of Interests}

The authors declare that there is no conflict of interests regarding the publication of this paper.

\section{Acknowledgments}

The authors would like to thank the Department of Science, Technology and Environment, Agartala, Tripura, India, and Tripura Renewable Energy Development Agency for their cooperation.

\section{References}

[1] V. J. Fesharaki, M. Dehghani, and J. J. Fesharaki, "The effect of temperature on photovoltaic cell efficiency," in Proceedings of the 1st International Conference on Emerging Trends in Energy Conservation (ETEC '11), Tehran, Iran, November 2011. 
[2] R. Siddiqui and U. Bajpai, "Deviation in the performance of solar module under climatic parameter as ambient temperature and wind velocity in composite climate," International Journal of Renewable Energy Research, vol. 2, no. 3, pp. 486-490, 2012.

[3] E. B. Ettah, E. E. Eno, and A. B. Udoimuk, "The effects of solar panel temperature on the power output efficiency Calabar, Nigeria," Journal of Association of Radiographers of Nigeria, vol. 23, pp. 16-22, 2009.

[4] A. R. Gxasheka, E. E. van Dyk, and E. L. Meyer, "Evaluation of performance parameters of PV modules deployed outdoors," Renewable Energy, vol. 30, no. 4, pp. 611-620, 2005.

[5] V. B. Omubo-Pepple, C. Israel-Cookey, and G. I. Alaminokuma, "Effects of temperature, solar flux and relative humidity on the efficient conversion of solar energy to electricity," European Journal of Scientific Research, vol. 35, no. 2, pp. 173-180, 2009.

[6] M. R. Abdelkader, A. Al-Salaymeh, Z. Al-Hamamre, and S. Firas, "A comparative analysis of the performance of monocrystalline and multicrystalline PV cells in semi arid climate conditions: the case of Jordan," Jordan Journal of Mechanical and Industrial Engineering, vol. 4, pp. 543-552, 2010.

[7] S. Armstrong and W. G. Hurley, "A new methodology to optimise solar energy extraction under cloudy conditions," Renewable Energy, vol. 35, no. 4, pp. 780-787, 2010.

[8] R. Siddiqui and U. Bajpai, "Statistical analysis of solar photovoltaic module output with temperature, humidity and wind velocity in composite climate," European Journal of Scientific Research, vol. 80, no. 4, pp. 447-456, 2012.

[9] Y. K. Sansui, G. R. Fajimi, and E. B. Babatunde, "Effects of ambient temperature on the performance of a photovoltaic solar system in a tropical area," The Pacific Journal of Science and Technology, vol. 12, pp. 176-180, 2011. 


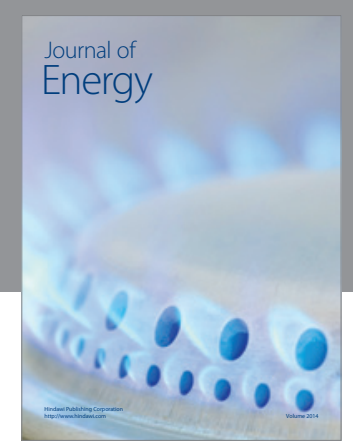

Journal of

Industrial Engineering
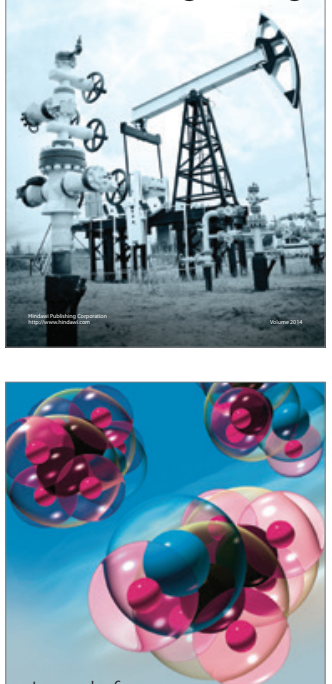

Fuels
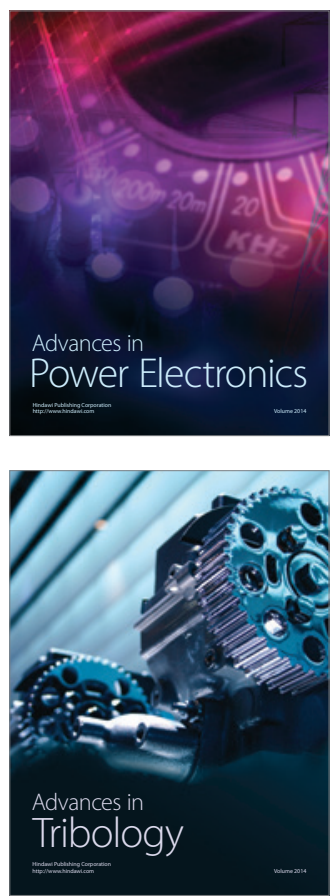

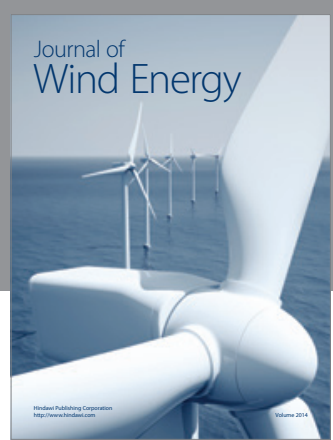

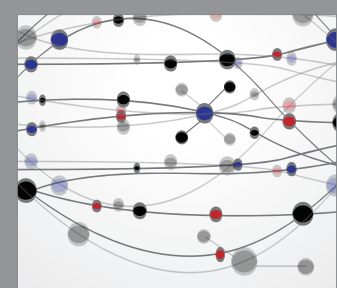

The Scientific World Journal

Submit your manuscripts at http://www.hindawi.com

Journal of

Structures
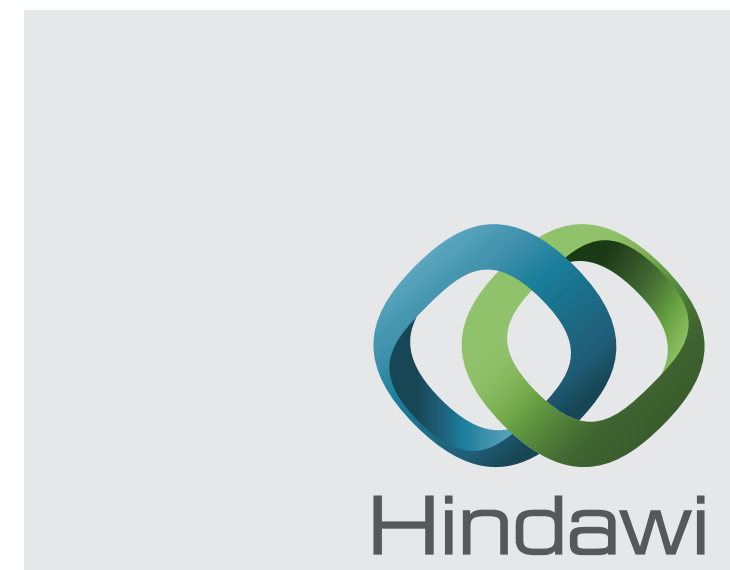

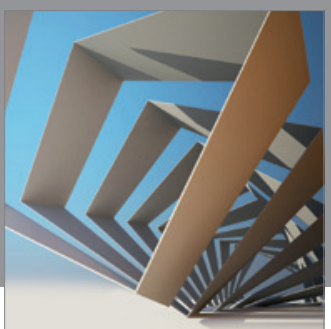

Rotating

Machinery
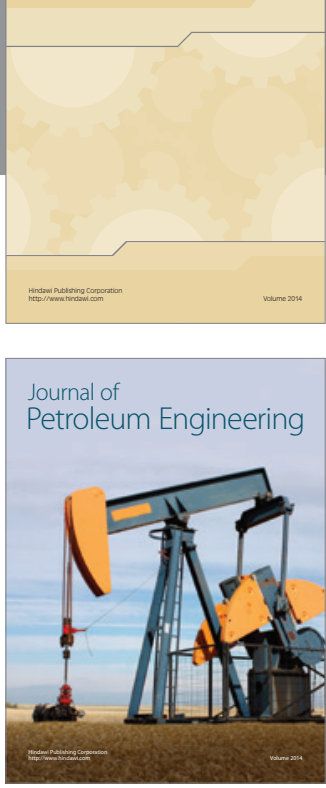

Journal of

Solar Energy
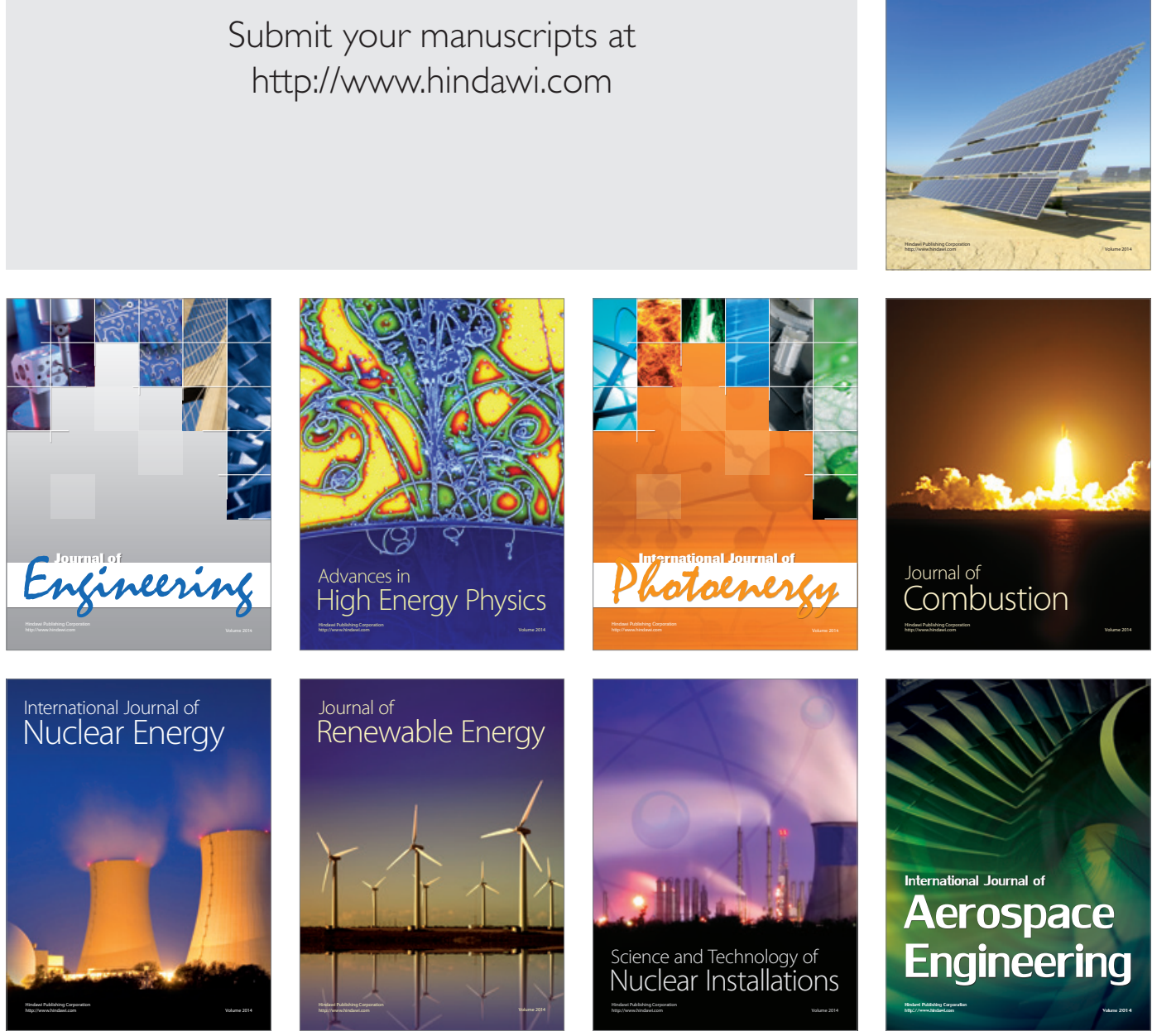